\title{
Reclassification of Bacteroides ureolyticus as Campylobacter ureolyticus comb. nov., and emended description of the genus Campylobacter
}

Correspondence

P. Vandamme

peter.vandamme@ugent.be

\author{
P. Vandamme ${ }^{1}$ L. Debruyne, ${ }^{1}$ E. De Brandt ${ }^{1}$ and E. Falsen ${ }^{2}$ \\ ${ }^{1}$ Laboratory of Microbiology, K. L. Ledeganckstraat 35, Universiteit Gent, B-9000 Ghent, Belgium \\ ${ }^{2}$ Culture Collection, Department of Clinical Bacteriology, University of Göteborg, Göteborg, Sweden
}

\begin{abstract}
The protein profiles, genomic amplified fragment length polymorphism patterns and 16S rRNA and cpn60 gene sequences of a diverse collection of 26 Bacteroides ureolyticus strains, along with published data on their DNA base, respiratory quinone and cellular fatty acid compositions, were used to reassess the taxonomy of this bacterial species. The results demonstrate that this organism is most appropriately allocated in the genus Campylobacter. The presence of much higher amounts of $18: 1 \omega 7 \mathrm{c}$ in its cellular fatty acid profile and its ability to digest gelatin and casein are the characteristics that differentiate it from present species of the genus Campylobacter. Therefore we propose to reclassify this species incertae sedis into the genus Campylobacter as Campylobacter ureolyticus with strain LMG $6451^{\top}\left(=\right.$ CCUG $7319^{\top}=$ NCTC $10941^{\top}$ ) as the type strain.
\end{abstract}

On the basis of genotypic, chemotaxonomic and phenotypic characteristics, the generically misclassified Bacteroides gracilis has been transferred into the genus Campylobacter as Campylobacter gracilis (Vandamme et al., 1995). In the same study it was unclear whether Bacteroides ureolyticus was to be reclassified as a member of the genus Campylobacter, or as a representative of a novel genus within the family Campylobacteraceae. Hence, it remained a species incertae sedis pending the isolation and characterization of additional B. ureolyticus-like bacteria. In the present study, the taxonomic status of a collection of 26 human B. ureolyticus strains from various clinical sources was re-evaluated using a polyphasic approach.

The strains used and their sources are listed in Supplementary Table S1 (available in IJSEM Online). Bacteriological purity was checked by plating and examining living and Gram-stained cells. The collection of strains examined included four well-characterized reference strains from a previous taxonomic study (LMG 6451 ${ }^{\mathrm{T}}$, LMG 8448, LMG 8449 and LMG 8450) and 22 human isolates (20

The GenBank/EMBL/DDBJ accession numbers for the 16S rRNA gene sequences of strains LMG 24746, LMG 24747, R-38115, LMG 8448 and R-37890 are FN401323-FN401327, respectively. The accession numbers for the cpn60 gene sequences of strains LMG 24746, R37890, LMG 6451', LMG 24747, R-38115 and LMG 8448 are FN421436-FN421441, respectively.

Numerical reproductions of whole-cell protein profiles and a corresponding UPGMA dendrogram, a neighbour-joining phylogenetic tree based on cpn60 gene sequences, a list of $B$. ureolyticus strains examined and their sources, and reciprocal DNA-DNA hybridization results are available with the online version of this paper. from Sweden, two from the USA) obtained between 1977 and 2005 (Supplementary Table S1).

The 26 strains were first analysed by means of whole-cell protein electrophoresis and amplified fragment length polymorphism analysis in order to reveal the taxonomic structure of this taxon. For whole-cell protein SDS-PAGE, all $B$. ureolyticus strains were grown on Mueller-Hinton agar supplemented with $5 \%$ horse blood and incubated at $37{ }^{\circ} \mathrm{C}$ for $48 \mathrm{~h}$ under micro-aerobic conditions (approx. $4 \% \mathrm{O}_{2}, 6.5 \% \mathrm{CO}_{2}, 6.5 \% \mathrm{H}_{2}, 83 \% \mathrm{~N}_{2}$ ). The preparation of whole-cell proteins and SDS-PAGE were performed as described by Pot et al. (1994). Normalization of densitometric traces was performed using the GelCompar version 4.2 software (Applied Maths). Numerical analysis was performed using the Pearson product moment correlation coefficient and UPGMA with BioNumerics 4.61 software. AFLP-analysis was performed as described by Debruyne et al. (2009) using the HindIII-HhaI restriction enzyme combination. One microlitre of the final product was analysed by capillary gel electrophoresis using an ABI 3130XL automated DNA sequencer. For every sample, $0.4 \mu \mathrm{l}$ of an internal lane standard (LIZ600, Applied Biosystems) was included. AFLP profiles were collected with the Data Collection software v 3.0 (Applied Biosystems), and the profiles generated were imported, using the CrvConv filter, into BioNumerics version 4.61 (Applied Maths) for normalization and further analysis. Similarity between normalized profiles was determined by the Pearson product moment correlation coefficient and a UPGMA dendrogram was reconstructed. 
Supplementary Figure S1 shows the result of the numerical comparison of the protein profiles of the 26 strains. As discussed by Taylor et al. $(1986,1987)$ the whole-cell protein profiles of $B$. ureolyticus strains differ mainly in the position of major protein bands in the molecular mass region of $36-52 \mathrm{kDa}$ (Taylor et al., 1987). The same observations have been reported for a range of species of the genus Campylobacter (e.g. Vandamme et al., 1990, 1991b, 1992) and different PAGE profile types within $B$. ureolyticus have been described (Taylor et al., 1986, 1987). Nevertheless, high DNA-DNA hybridization values among strains representing such different PAGE profile types have been obtained (Taylor et al., 1986), as for species of the genus Campylobacter (e.g. Vandamme et al., 1990, 1991b, 1992). The numerical analysis of the AFLP profiles also revealed considerable diversity among the 26 strains (Fig. 1). Twenty one clinical isolates formed a single but heterogeneous cluster grouping with the type strain and two additional reference strains (Vandamme et al., 1995). A third reference strain (LMG 8448) and a single clinical isolate (R-37787) grouped separately in the dendrogram (Fig. 1); the protein profiles of the latter two isolates, nevertheless, were not aberrant from those of the other strains examined (Supplementary Fig. S1).

We subsequently performed DNA-DNA hybridizations among strains representing four different PAGE profile types (LMG 6451 ${ }^{\mathrm{T}}$, LMG 24746, LMG 24747 and R-37890; marked in Supplementary Fig. S1 and Fig. 1 in bold type). DNA-DNA hybridizations were performed with photobiotin-labelled probes in microplate wells (Ezaki et al., 1989), using an HTS7000 Bio Assay Reader (Perkin Elmer) for the fluorescence measurements. The hybridization temperature was $30{ }^{\circ} \mathrm{C}$. Reciprocal experiments were performed for every pair of strains. The DNA-DNA hybridization values obtained were generally above $70 \%$ (Supplementary Table S2) confirming results by Taylor et al. (1986).

One of the key issues for revising the classification of $B$. ureolyticus is its phylogenetic position relative to members of the genus Campylobacter. For that reason, we examined the phylogenetic position of strains LMG $6451^{\mathrm{T}}$, LMG 8448, LMG 24746, LMG 24747, R-37890 and R-38115 (marked in Supplementary Fig S1 and Fig. 1 with an asterisk) through comparative $16 \mathrm{~S}$ rRNA and cpn60 gene sequence analysis. 16S rRNA gene amplification, purification and sequencing were performed as described by Vandamme et al. (2006). Sequence assembly was performed using the BioNumerics 4.61 software, and selected sequences representing members of the genus Campylobacter and related bacteria were aligned by using CLUSTAL X. Subsequently, the aligned sequences were imported into the BioNumerics software for phylogenetic analyses and bootstrap analysis (500 replicates). Unknown bases were discarded for the analysis and phylogenetic trees were reconstructed by using the neighbour-joining, maximumlikelihood and maximum-parsimony methods. The similarity of the 16S rRNA gene sequences of the six $B$. ureolyticus strains was $>99 \%$; the similarity towards species of the genus Campylobacter was in the range of 91-93\%, whereas the similarity towards other representatives of the class Epsilonproteobacteria was below $90 \%$. When varying the number of reference strains included in the phylogenetic analysis, B. ureolyticus strains clustered either at the periphery of the Campylobacter lineage, or as a deep branching line of descent among the Campylobacter species (Fig. 2). This confirms previous observations (Vandamme et al., 1995). When considering the taxonomic position of $B$. ureolyticus in the single $16 \mathrm{~S}$ rRNA tree harbouring all sequenced prokaryotic type strains of the 'All-Species Living Tree' project (http://www.arb-silva.de/ projects/living-tree/), B. ureolyticus clusters among the species of the genus Campylobacter. When applying maximum-parsimony or maximum-likelihood clustering methods, the $B$. ureolyticus cluster also groups among the Campylobacter species (data not shown).

Sequence analysis of protein encoding genes provides a higher taxonomic resolution compared to $16 \mathrm{~S}$ rRNA gene sequence analysis. In the genus Campylobacter and related bacteria, partial cpn60 gene sequence-based phylogeny correlates with 16S rRNA gene sequence-based phylogeny but provides a better resolution among closely related species (Kärenlampi et al., 2004; Hill et al., 2006; Debruyne et al., 2009). The partial cpn60 gene sequences (555 bp) of the six strains analysed by $16 \mathrm{~S}$ rRNA gene sequence analysis were determined as described by Hill et al. (2006) and modified by Debruyne et al. (2009). Sequencing and further analyses were performed as described above. The similarity of the cpn60 gene sequences of the five strains was $>95 \%$; the similarity with species of the genus Campylobacter was below $83 \%$. A neighbour-joining tree representing the cpn60 gene phylogeny is presented in Supplementary Fig. S2. Again, when varying the number of reference strains included in the phylogenetic analysis, B. ureolyticus strains clustered either at the periphery of the Campylobacter lineage, or as a deep branching line of descent among the Campylobacter species.

Several additional characteristics have been determined for B. ureolyticus strains. Their DNA base composition was examined in several studies and is in the range of 2830 mol\% (Jackson \& Goodman, 1978; Taylor et al., 1986; Vandamme et al., 1991a). Vandamme et al. (1995) showed that B. ureolyticus ATCC $33387^{\mathrm{T}}\left(=\mathrm{LMG} 6451^{\mathrm{T}}\right)$ comprised menaquinone (MK)-5, MK-6, and a methylsubstituted menaquinone-6 [2, (5 or 8 )-dimethyl-3-farnesyl-farnesyl-1,4-naphthoquinone] designated ${ }^{*} \mathrm{MK}-6$, the so-called thermoplasmaquinone, as respiratory quinones. The latter was present as a major compound. This overall menaquinone pattern was essentially identical to that of members of the genus Campylobacter. The cellular fatty acid composition of $B$. ureolyticus differed primarily from those of the species of the genus Campylobacter examined by the presence of much higher amounts of $18: 1 \omega 7 c$. 


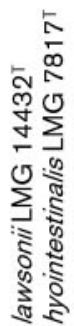

เัต

은

๑)

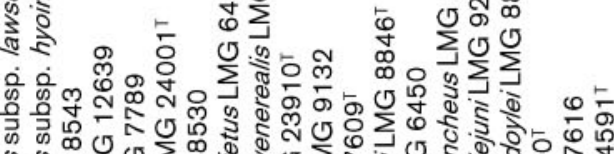

क.

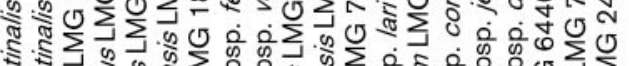

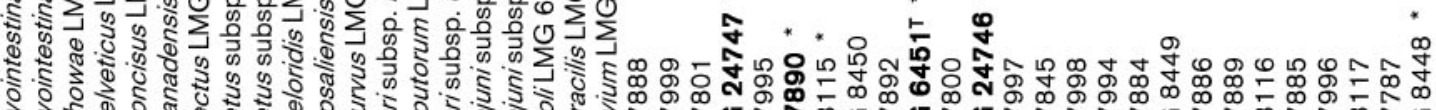

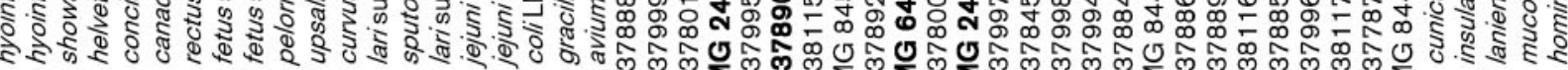

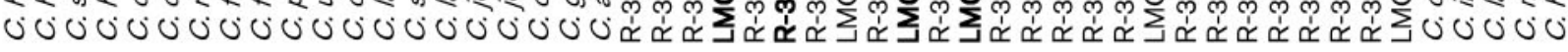

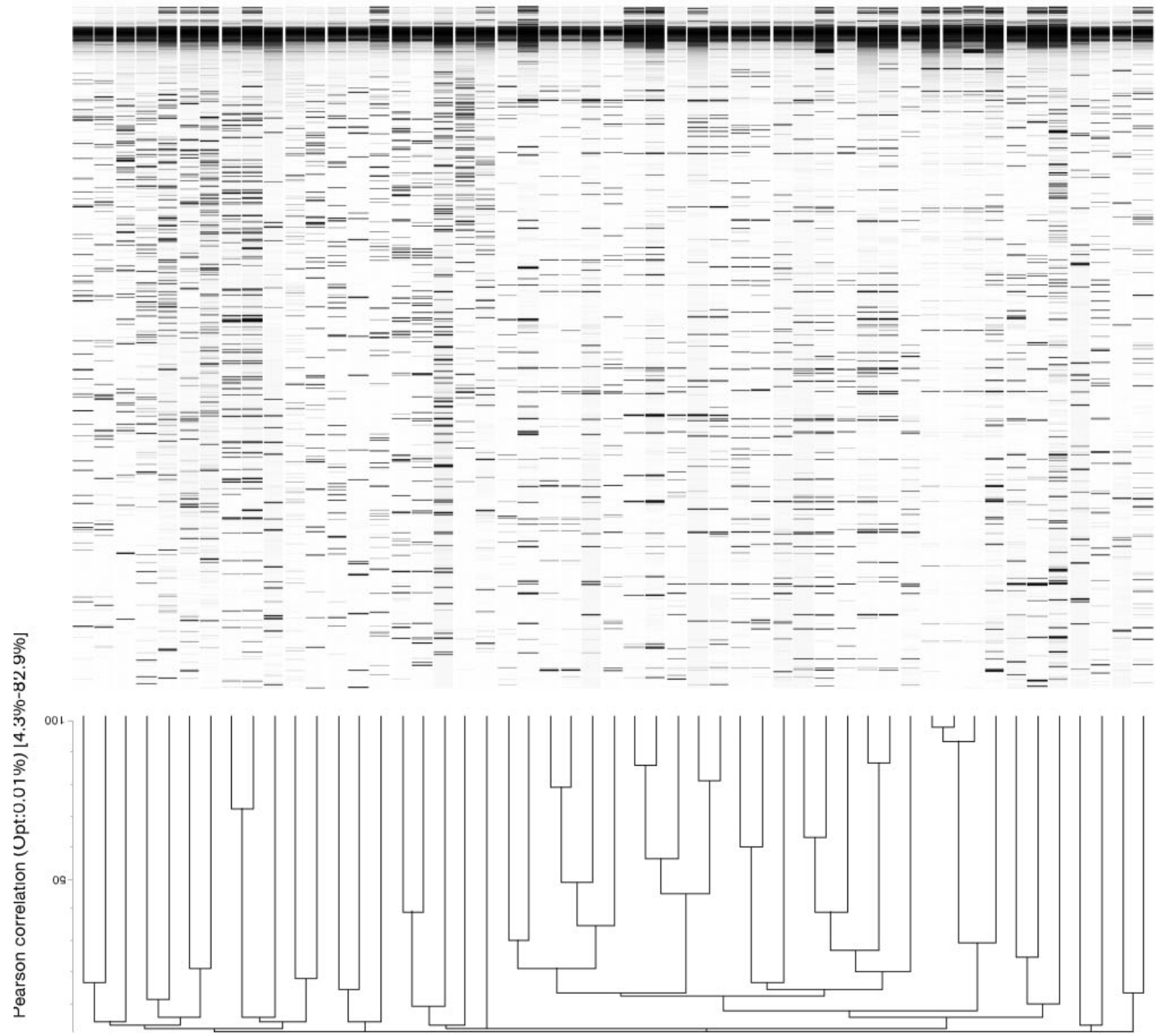


The reclassification of B. ureolyticus is not straightforward. In the present study, we provide polyphasic taxonomic information on a diverse set of $26 \mathrm{~B}$. ureolyticus strains. Two of these (LMG 8448 and R-37787) grouped separately in the AFLP dendrogram, but conformed to the other strains examined in terms of whole-cell protein profile and cpn60 and 16S rRNA gene sequences. Since the 1995 study, the number of Campylobacter taxa with validly published names has nearly doubled and several of the characteristics that then differentiated B. ureolyticus from campylobacters are no longer valid. Maximum-likelihood and parsimony analyses of the 16S rRNA gene sequences allocate this organism in the genus Campylobacter; neighbour-joining based analyses are equivocal. Its fatty acid composition (the relative proportion of essentially one fatty acid) and the hydrolysis of gelatin and casein (Jackson \& Goodman, 1978; Duerden et al., 1989; Taylor et al., 1986) remain the key differential characteristics towards the current Campylobacter species. In addition, the presence of urease activity also distinguishes $B$. ureolyticus from most other campylobacters (only some Campylobacter lari and Campylobacter sputorum strains are urease-positive).

It serves no purpose to preserve the taxonomic status of this organism as a species incertae sedis. We feel it is most appropriate to formally reclassify this well-characterized taxon within the genus Campylobacter as Campylobacter ureolyticus comb. nov.

\section{Emended description of the genus Campylobacter Sebald and Véron 1963, 907 ${ }^{\mathrm{AL}}$}

Campylobacter (cam.py'lo.bac.ter. Gr. adj. kampulos bent, curved; N.L. masc. n. bacter rod; N.L. masc. n. Campylobacter a curved rod).

This emended description is based on the data provided by On \& Holmes (1995), On et al. (1996) and Vandamme et al. (2005).

Cells of most species are slender, spirally curved rods, $0.2-$ $0.8 \mu \mathrm{m}$ wide and $0.5-5 \mu \mathrm{m}$ long; cells of some species are predominantly curved or straight rods. Rods may have one or more spirals and can be as long as $8 \mu \mathrm{m}$; they also appear S-shaped and gullwinged when two cells form short chains. Non-spore-forming. Cells in old cultures may form spherical or coccoid bodies. Cells have a multilaminar polar membrane at both ends of the cell that is located under the cytoplasmic membrane. Gram-negative. Cells of most species are motile with a characteristic corkscrewlike motion by means of a single, polar, unsheathed flagellum at one or both ends of the cell. The flagella may be two to three times the length of the cells. Cells of other species are non-motile (C. gracilis) or have multiple flagella (Campylobacter showae). Occasionally, differences in the number of flagella shown by cells in a single culture are seen (Campylobacter hyointestinalis).

Microaerophilic, with a respiratory type of metabolism. Several species require anaerobiosis for optimal growth and 


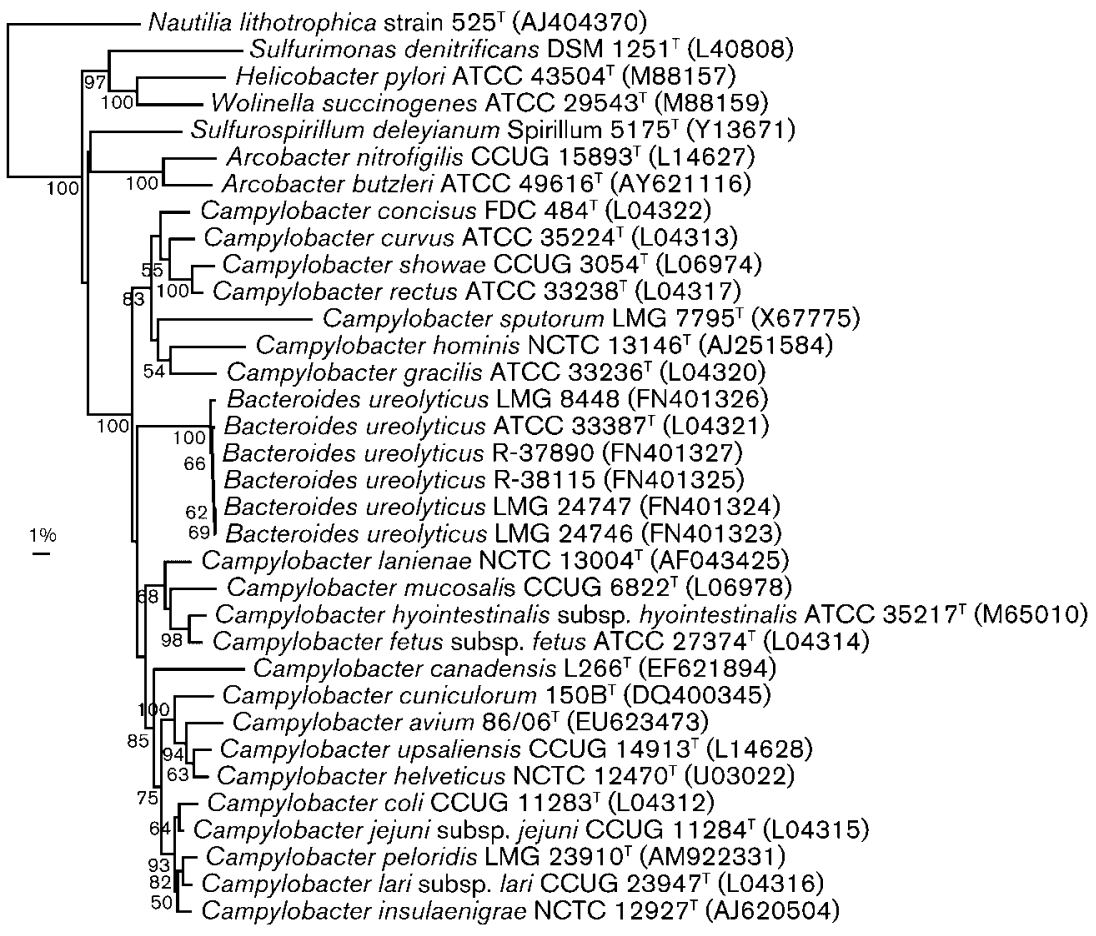

Fig. 2. Neighbour-joining phylogenetic tree based on 16S rRNA gene sequences showing the position of $B$. ureolyticus and related bacteria. Bar, $1 \%$ difference in nucleotide sequence as determined by measuring the length of horizontal lines connecting two species. Bootstrap values are indicated at the nodes; values of less than $50 \%$ are not shown. grow only microaerobically in the presence of fumarate with formate or hydrogen. Require an oxygen concentration between 3 and $15 \%$ and a carbon dioxide concentration of 3 to $15 \%$. Grow at $35-37{ }^{\circ} \mathrm{C}$, not at $4{ }^{\circ} \mathrm{C}$. Chemo-organotrophs. Carbohydrates are neither fermented nor oxidized. No acid or neutral end-products produced. Serum or blood enhances, but is not required for, growth. Energy is obtained from amino acids or tricarboxylic acid cycle intermediates, not from carbohydrates. Starch and tyrosine are not hydrolysed. Typically non-proteolytic, yet C. ureolyticus is capable of digesting gelatin and casein (although C. showae is able to grow on casein hydrolysis test media, it does not hydrolyse casein). Methyl red and Voges-Proskauer negative. Oxidase activity is present in all species except $C$. gracilis and sporadic isolates of Campylobacter concisus and C. showae. Arylsulfatase activity is reported in some species, but no lipase or lecithinase activity. Most species reduce nitrate. Pigments are not produced. Most species are pathogenic for man and animals. Found in the reproductive organs, intestinal tract and oral cavity of man and animals.

The mol\% G $+\mathrm{C}$ of the DNA ranges from 29 to 47 (thermal denaturation method). Menaquinone-6 (2-methyl-3-farnesyl-farnesyl-1,4-naphthoquinone) and a methyl-substituted menaquinone-6 [2, (5 or 8)-dimethyl-3-farnesyl-farnesyl1,4-naphthoquinone] have been reported as major respiratory quinones. Internal transcribed spacers or intervening sequences occur in the $16 \mathrm{~S}$ or $23 \mathrm{~S}$ rRNA genes of strains of several species.

The type species is Campylobacter fetus (Smith and Taylor 1919) Sebald and Véron 1963, 907.

\section{Description of Campylobacter ureolyticus comb. nov.}

Campylobacter ureolyticus [ur'e.o.ly.ti.cus N.L. fem. n. urea urea; N.L. masc. adj. lyticus (from Gr. masc. adj. lutikos), able to loose, able to dissolve; N.L. masc. adj. ureolyticus urea dissolving].

Basonym: Bacteroides ureolyticus Jackson and Goodman $1978,199^{\mathrm{AL}}$.

The description is mainly based on data for B. ureolyticus presented by On \& Holmes (1995), On et al. (1996) and Vandamme et al. (2005). Additional references are provided when appropriate.

Cells are $0.5 \mu \mathrm{m}$ in diameter and $1.5-4 \mu \mathrm{m}$ long. Nonmotile. Filaments exceeding $20 \mu \mathrm{m}$ in length may occur. Cells of some strains have polar tufts of long pili in electron micrographs and exhibit 'twitching' motility. The pili sometimes form a bundle and may be mistaken for flagella with light microscopy. Translucent colonies are produced on blood agar bases. Different colony types are observed: small pinpoint colonies, $1 \mathrm{~mm}$ in diameter, or spreading colonies up to $5 \mathrm{~mm}$ in diameter. Agar pitting is medium dependent but most $(90 \%)$ strains exhibit this trait after three days of anaerobic growth on $5 \%$ blood agar. Optimal growth in hydrogen-enriched microaerobic conditions. Does not grow microaerobically on common agar bases in an atmosphere without hydrogen. Will not grow in air, in a $\mathrm{CO}_{2}$-enriched atmosphere, or in an atmosphere containing $5 \% \mathrm{O}_{2}, 10 \% \mathrm{CO}_{2}$ and $85 \% \mathrm{~N}_{2}$ on common agar bases. Anaerobic growth occurs with formate and fumarate in the medium. Fumarate is reduced to succinate; fumarate, 
nitrate and nitrite serve as electron acceptors. Grows at 30 and $37{ }^{\circ} \mathrm{C}$, but not at $25^{\circ} \mathrm{C}$; strain-dependent growth at $42{ }^{\circ} \mathrm{C}$. Grows on media containing $0.1 \%$ trimethylamine- $N$ oxide, $1 \%$ glycine, $0.05 \%$ sodium fluoride, $0.032 \%$ methyl orange or $2-4 \% \mathrm{NaCl}$; no growth in the presence of $1.5-2 \%$ bile, $0.04 \%$ 2,3,5-triphenyl-tetrazolium chloride or $0.05 \%$ basic fuchsin; strain-dependent growth in the presence of $1 \%$ bile, $0.1 \%$ potassium permanganate, $0.02 \%$ sodium arsenite, $0.02 \%$ safranine, $0.0005 \%$ crystal violet or $0.01 \%$ janus green. Most strains grow on nutrient agar and buffered charcoal yeast medium; growth on Campylobacter charcoal deoxycholate medium, Campylobacter minimal medium and MacConkey agar is strain-dependent.

Oxidase- and urease-activity is present, but no hydrolysis of hippurate, DNase activity, alkaline phosphatase activity, reduction of triphenyl-tetrazolium chloride, or production of hydrogen sulphide in triple-sugar iron medium. Gelatinase activity is present (Jackson \& Goodman, 1978). Nitrate is reduced, but not selenite. No pigment production. Alpha-haemolysis and catalase activity of indoxyl acetase are strain-dependent. No hydrolysis of casein or growth on casein medium when performed as described by Cowan (1974); casein hydrolysis is weak (Jackson \& Goodman, 1978), as described by Jackson et al. (1971), but strain-dependent as described by Taylor \& Owen (1984). As with other preferentially anaerobic species of the genus Campylobacter, strains are susceptible to a range of antibiotics including cephalothin $\left(32 \mathrm{mg} \mathrm{l}^{-1}\right)$, nalidixic acid $\left(32 \mathrm{mg} \mathrm{l}^{-1}\right)$, carbenicillin $\left(32 \mathrm{mg} \mathrm{l}^{-1}\right)$, cefoperazone $\left(64 \mathrm{mg} \mathrm{l}^{-1}\right)$ and 5-fluorouracil $\left(100 \mathrm{U} \mathrm{l}^{-1}\right)$. Contains cytochromes b and c. Menaquinone-6 (2methyl-3-farnesyl-farnesyl-1,4-naphthoquinone) and a methyl-substituted menaquinone- 6 [2, (5 or 8)-dimethyl3-farnesyl-farnesyl-1,4-naphthoquinone] have been reported as major respiratory quinones. The $\mathrm{mol} \% \mathrm{G}+\mathrm{C}$ of the DNA is 28 to 30 (thermal denaturation method).

Strains have been isolated from superficial ulcers and soft tissue infections, non-gonococcal, non-chlamydial urethritis, and periodontal disease. Pathogenicity is difficult to assess because strains are mostly recovered from mixed infections.

The type strain is LMG $6451^{\mathrm{T}}\left(=\right.$ CCUG $7319^{\mathrm{T}}=$ NCTC $\left.10941^{\mathrm{T}}\right)$.

\section{Acknowledgements}

P.V. and L.D. are indebted to the Fund for Scientific Research Flanders (Belgium) for financial support.

\section{References}

Cowan, S. T. (1974). Cowan and Steel's Manual for the Identification of Medical Bacteria, 2nd edn. Cambridge: Cambridge University Press.

Debruyne, L., On, S. L. W., De Brandt, E. \& Vandamme, P. (2009). Novel Campylobacter lari-like bacteria from humans and molluscs: description of Campylobacter peloridis sp. nov., Campylobacter lari subsp. concheus subsp. nov. and Campylobacter lari subsp. lari subsp. nov. Int J Syst Evol Microbiol 59, 1126-1132.

Duerden, B. I., Eley, A., Goodwin, L., Magee, J. T., Hindmarch, J. M. \& Bennett, K. W. (1989). A comparison of Bacteroides ureolyticus isolates from different clinical sources. J Med Microbiol 29, 63-73.

Ezaki, T., Hashimoto, Y. \& Yabuuchi, E. (1989). Fluorometric deoxyribonucleic acid-deoxyribonucleic acid hybridization in microdilution wells as an alternative to membrane filter hybridization in which radioisotopes are used to determine genetic relatedness among bacterial strains. Int J Syst Bacteriol 39, 224-229.

Hill, J. E., Paccagnella, A., Law, K., Melito, P. L., Woodward, D. L., Price, L., Leung, A. H., Ng, L.-K., Hemmingsen, S. M. \& Goh, S. H. (2006). Identification of Campylobacter spp. and discrimination from Helicobacter and Arcobacter spp. by direct sequencing of PCRamplified cpn60 sequences and comparison to cpnDB, a chaperonin reference sequence database. J Med Microbiol 55, 393-399.

Jackson, F. L. \& Goodman, Y. E. (1978). Bacteroides ureolyticus, a new species to accommodate strains previously identified as 'Bacteroides corrodens, anaerobic'. Int J Syst Bacteriol 28, 197-200.

Jackson, F. L., Goodman, Y. E., Bel, F. R., Wong, P. C. \& Whitehouse, R. L. S. (1971). Taxonomic status of facultative and strictly anaerobic 'corroding bacilli' that have been classified as Bacteroides corrodens. J Med Microbiol 4, 171-184.

Kärenlampi, R. I., Tolvanen, T. P. \& Hänninen, M. L. (2004). Phylogenetic analysis and PCR-restriction fragment length polymorphism identification of Campylobacter species based on partial groEL gene sequences. J Clin Microbiol 42, 5731-5738.

On, S. L. W. \& Holmes, B. (1995). Classification and identification of campylobacters, helicobacters and allied taxa by numerical analysis of phenotypic characters. Syst Appl Microbiol 18, 374-390.

On, S. L. W., Holmes, B. \& Sackin, M. (1996). A probability matrix for the identification of campylobacters, helicobacters, and allied taxa. J Appl Bacteriol 81, 425-432.

Pot, B., Vandamme, P. \& Kersters, K. (1994). Analysis of electrophoretic whole-organism protein fingerprints. In Chemical Methods in Prokaryotic Systematics, pp. 493-521. Edited by M. Goodfellow \& A. G. O’Donnell. Chichester: Wiley.

Taylor, A. J. \& Owen, R. J. (1984). Morphological and chemical characteristics of anaerobic curved rod-shaped bacteria from the female genital tract. In Bacterial Vaginosis, pp. 97-106. Edited by P.-A. Mårdh \& D. Taylor-Robinson. Stockholm: Almqvist and Wiksell International.

Taylor, A. J., Dawson, C. A. \& Owen, R. J. (1986). The identification of Bacteroides ureolyticus from patients with non-gonococcal urethritis by conventional biochemical tests and by DNA and protein analyses. J Med Microbiol 21, 109-116.

Taylor, A. J., Costas, M. \& Owen, R. J. (1987). Numerical analysis of electrophoretic protein patterns of Bacteroides ureolyticus clinical isolates. J Clin Microbiol 25, 660-666.

Vandamme, P., Pot, B., Falsen, E., Kersters, K. \& De Ley, J. (1990). Intra- and interspecific relationships of veterinary campylobacters revealed by numerical analysis of electrophoretic protein profiles and DNA: DNA hybridizations. Syst Appl Microbiol 13, 295-303.

Vandamme, P., Falsen, E., Rossau, R., Hoste, B., Segers, P., Tytgat, R. \& De Ley, J. (1991a). Revision of Campylobacter, Helicobacter, and Wolinella taxonomy: emendation of generic descriptions and proposal of Arcobacter gen. nov. Int J Syst Bacteriol 41, 88-103.

Vandamme, P., Pot, B. \& Kersters, K. (1991b). Differentiation of campylobacters and Campylobacter-like organisms by numerical analysis of one-dimensional electrophoretic protein patterns. Syst Appl Microbiol 14, 57-66. 
Vandamme, P., Dewettinck, D. \& Kersters, K. (1992). Application of numerical analysis of electrophoretic protein profiles for the identification of thermophilic campylobacters. Syst Appl Microbiol 15, 402-408.

Vandamme, P., Daneshvar, M. I., Dewhirst, F. E., Paster, B. J., Kersters, K., Goossens, H. \& Moss, C. W. (1995). Chemotaxonomic analyses of Bacteroides gracilis and Bacteroides ureolyticus and reclassification of $B$. gracilis as Campylobacter gracilis comb. nov. Int J Syst Bacteriol 45, 145-152.
Vandamme, P., Dewhirst, F. E., Paster, B. J. \& On, S. L. W. (2005). Genus I. Campylobacter Sebald and Véron 1963, $907^{\mathrm{AL}}$ emend. Vandamme, Falsen, Rossau, Hoste, Segers, Tytgat and De Ley 1991a, 98. pp. 11471160. In Bergey's Manual of Systematic Bacteriology, vol. 2. Edited by D. J. Brenner, N. R. Krieg, J. T. Staley \& G. M. Garrity. New York: Springer. Vandamme, P., Holmes, B., Bercovier, H. \& Coenye, T. (2006). Classification of Centers for Disease Control group eugonic fermenter (EF)-4a and EF-4b as Neisseria animaloris sp. nov. and Neisseria zoodegmatis sp. nov., respectively. Int J Syst Evol Microbiol 56, 1801-1805. 